\title{
25 Research Square \\ Clinical characteristics, outcomes and follow-up of COVID-19 infection in cancer patients
}

\section{Minghao Fang ( $\nabla$ fangmh8364@163.com )}

Tongji Hospital, Tongji Medical College, Huazhong University of Science and Technology https://orcid.org/0000-0001-5310-8128

\section{Jianmin Ling}

Tongji Hospital, Tongji Medical College, Huazhong University of Science and Technology

\section{Yanqing Wu}

Wuhan Union Hospital

\section{Zhaohua Wang}

Tongji Hospital, Tongji Medical College, Huazhong University of Science and Technology

\section{Le Yang}

Tongji Hospital, Tongji Medical College, Huazhong University of Science and Technology

\section{Research Article}

Keywords: COVID-19, SARS-CoV-2, cancer, lymphopenia, cytokines, virus carriers

Posted Date: June 8th, 2020

DOl: https://doi.org/10.21203/rs.3.rs-33276/v1

License: (c) (i) This work is licensed under a Creative Commons Attribution 4.0 International License.

Read Full License 


\section{Abstract}

Purpose: The study is to describe the clinical characteristics, outcomes and follow-up of cancer patients with COVID-19.

Methods: Clinical records, demographic data, signs and symptoms, laboratory results, cytokine profiles, chest CT scans, comorbidities, treatments, clinical outcomes, and RT-PCR of SARS-CoV-2 after discharge were retrospectively collected for fifty-six cancer patients with laboratory-confirmed COVID-19 pneumonia who were admitted to Tongji Hospital of Huazhong University of Science and Technology, Wuhan, China, from Feb 1 to Apr 1, 2020. Evidence of cytokine profiles were assessed by testing for the IL1 $\beta$, IL2R, IL6, IL8, IL10, and TNF - $a$ in the peripheral blood of severe acute respiratory syndrome corona virus 2 (SARSCoV-2) infected cancer patients.

Results: Of 2143 patients with COVID-19, 56 cancer patients were included. The patients were divided into two groups, as cancer survivors, and cancer non-survivors. 12 (21\%) patients with lymphopenia (0.5 [0.30.7]) had died during hospital stay. In non-survivors, IL2R, IL6, and IL10 were higher. 3(6.8\%) cancer survivors with COVID-19 had positive RT-PCR test results again shortly after discharge.

Conclusion: The mortality rate of COVID-19 among cancer patients are considerable. Cancer nonsurvivors are characterized by more severe lymphopenia and a higher levels of cytokines. Recovered cancer survivors still may be virus carriers.

\section{Introduction}

Cases of a novel coronavirus known as SARS-CoV-2 are first reported in Wuhan, Hubei province, China, in December 2019 and have since spread rapidly worldwide[1]. Currently, the world is facing a medical emergency[2]. As of this writing, more than 2 million patients are known to have been infected around the world. Thousands of cases have died every day due to lack of adequate medical resources, specifific treatments, and lack of approved vaccine [3].

Previous studies report clinical characteristics, course and outcomes mainly focused on non-cancer adults[4]. However, there are only few studies about the effects of COVID-19 on the cancer patients[5-7]. According to previous reports in the literature, patients with cancer are suggested to have a higher risk of severe complications caused by the SARS-CoV-2[8]. Although patients with cancer represented a heterogeneous population, most studies tend to show they were more susceptible to infection than general patients because of their systemic immunosuppressive state due to cancer itself, cancer treatment, or both $[9,10]$.

However, these studies do not find enough differences in the probability of developing severe adverse events among the various types of cancers[11]. Liang et al is questioned for its small sample size and method, making it difficult to extrapolate any correctly and specifically results to the cancer patient population[5]. Taken altogether, the current evidence remains insufficient to elucidate a conclusive 
association between cancer and COVID-19[12]. What are the main risk factors affecting the prognosis of patients with cancer, and how different cytokine profiles change in patients with cancer during COVID-19 is remain largely obscure[13]. Therefore, more specific information need to be known include whether cancer survivors with COVID-19 pneumonia will develop distinct clinical manifestations from cancer non-survivors, whether cancer patients are more likely to reduce immunity or to have a poorer prognosis, and whether recovered cancer patients still may be virus carriers. At present, there is no relevant literature report about the occurrence of positive RT-PCR after discharge in cancer patients with COVID. Make these issues clear contribute to the surveillance or treatment decision-making.

In this study, we investigated cancer patients with confirmed SARS-CoV-2 pneumonia who were admitted to Tongji Hospital of Huazhong University of Science and Technology. Cancer non-survivors are characterized by a higher levels of multiple cytokines than cancer survivors. Cancer patients with COVID19 who met criteria for discharge may have recurrent positive RT-PCR test results out of hospital later.

\section{Methods}

\section{Study design and patients}

We retrospectively analysed patients with cancer from Feb 1, 2020, to Apr 1, 2020, who had been diagnosed with SARS-CoV-2 pneumonia, according to the National Health Commission of People's Republic of China as previously described[14]. Diagnosis of cancer patients was achieved by reviewing admission logs and histories from all available electronic medical records.

This study was approved by the Medical Ethical Committee of Tongji Hospital of Huazhong University of Science and Technology. Written informed consent was exempted due to the unexpected severity of this infectious disease.

\section{Data collection}

We obtained data on demographic, clinical, laboratory, cytokine profiles, radiography, treatment, and outcome from patients' electronic medical records. If any data were missing from the records was needed, we collected data by direct communication with attending doctors, involved health care providers and their families. All data were checked by two physicians (JM and YW).

As of the data cutoff on Apr 1 2020, we have collected 79 cases from Tongji hospital. All patients were diagnosed with RT-PCR confirmed COVID-19 disease. We excluded 23 cases because of insufficient records of previous disease history. We collected data on age, sex, exposure history, malignancy histories(gastrointestinal cancers, leukemia and lymphoma, lung cancer, kidney and bladder cancers, breast cancer, gynecological cancer, other cancers), chronic medical histories (smoking, hypertetion, diabetes, chronic cardiac disease, chronic pulmonary disease, cirrhosis, and central nervous system diseases), symptoms on admission (fever, cough, sputum, dyspnoea, diarrhea, nausea, vomiting, fatigue, 
muscular pain, and headache), vital signs at hospital admission (heart rate, respiratory rate, blood pressure, blood oxygen saturation), laboratory values on admission (White blood cell count, lymphocyte count, platelet count, haemoglobin concentration, D-dimer, transaminase, renal functions, lactate dehydrogenase, NT-proBNP), and cytokine profiles(IL1ß, IL2R, IL6, IL8, IL10, and TNF - a), coexisted infection, treatment(oxygen therapy, antiviral agents, antibacterial agents, anticoagulant, corticosteroids, and immuno globulin), complication, living status, as well as positive RT-PCR test results (in cancer patients recovered rrom COVID-19).

\section{Statistical analysis}

Continuous variables were expressed as median (IQR) or mean (SD) and compared with the MannWhitney $U$ test or independent sample t test; We expressed categorical variables as number (\%) and compared data by $\chi^{2}$ test or Fisher's exact test between Survivors and non- Survivors.

Tests were two-sided with statis-tically significance set at a less than $0 \cdot 05$. Statistical analyses were done using the Statistical Package for Social Science (SPSS) software(Version 20.0), unless otherwise indicated.

\section{Results}

As of the data cutoff on Apr 1, 2020, 2143 cases diagnosed with laboratory-confirmed SARS-Cov-2 pneumonia had been collected from Tongji Hospital of Huazhong University of Science and Technology in Wuhan, Hubei province. 2087 (97.4\%) were considered ineligible, including the patients who had no cancer, incomplete clinical information, or cardiac arrest immediately after admission. $56(2.6 \%)$ patients with cancer were included and analysed in this study (figure 1).. Cancer patients with COVID-19 were divided into two groups, as cancer Survivors and cancer non-Survivors. The median age was 64 years (IQR 54-71; table 1).. 32 (57\%) were men. Less than half had underlying diseases (27 [48\%]), including hypertension (23 [41\%]), diabetes (7 [12.5\%]), and chronic cardiac disease (5 [9\%]). $16(29 \%)$ had direct exposure to family members with confirmed or highly suspected SARS-CoV-2 infection.

The most common symptoms at onset of illness were fever (47 [84\%] of 56 patients), cough (39 [70\%]), dyspnoea (34 [61\%]) and fatigue 18 [32\%]).The vital signs (heart rate, systolic pressure, and blood oxygen saturation,table 1) of patients on admission were much less stable in non-survivors. The median duration from onset to hospitalization was shorter in cancer non-Survivors (4.5 days [IQR 2.3-9.5]) than cancer Survivors (14.5 days [IQR 6.3-19]).

The blood counts of patients on admission showed lymphopenia (lymphocyte count, 0.5 [0.3-0.7]; table 2).. Haemoglobi (87 [48-126]) and Platelet count level (114 [11-217]) were lower in cancer non-survivors. Prothrombin time, Lactate dehydrogenase and NT-proBNP were higher in cancer non-survivors (median prothrombin time $15 \mathrm{~s}$ [14-17]; median Lactate dehydrogenase level $453 \mathrm{U} / \mathrm{L}$ [179-551]; median NTproBNP $565 \mathrm{pg} / \mathrm{mL}$ [370-1418]) than in cancer non-survivors (median prothrombin time $14 \mathrm{~s}$ [14-14], $\mathrm{p}=$ 
0.03; median Lactate dehydrogenase level $239 \mathrm{U} / \mathrm{L}$ [200-318], $\mathrm{p}=0.048$; median NT-proBNP $137 \mathrm{pg} / \mathrm{mL}$ [48-314], $\mathrm{p} \otimes 0.001)$. Further comparison between cancer survivors and cancer non-survivors showed that plasma concentrations of IL2R, IL6, and IL10 were higher in cancer non-survivors than cancer survivors (table 2)..

All patients had cancer. Major cancer types included gastrointestinal cancers (13[23\%] of 56 patients, table 3),, leukemia and lymphoma (10[18\%], $p=0.02)$, and lung cancer $(9[16 \%])$. Half of patients died of ARDS (6[50\%]). Among the 56 patients, 7 (12.5\%) patients had a history of anti-cancer therapy including surgery, chemotherapy or radiotherapy within one month before hospitalization; $3(6.8 \%)$ patients in the survival group and $4(33.3 \%)$ patients in the non-survival group $(p=0.049)$ respectively. $14(25 \%)$ patients were treated with mechanical ventilation, and nine (16\%) with renal replacement therapy (table 3).. 46 (82\%) patients received antiviral agents, 49 (94\%) received antibacterial agents, $19(34 \%)$ received glucocorticoids, and 12 (21\%) patients received immunoglobulin (table 3 )..

Among 56 cancer patients with COVID-19, 12 (21\%) patients had died within 28 days. Compared with survivors, non-survivors were more likely to have leukemia and lymphoma( $5[42 \%]$ patients vs $5[11 \%]$ patients). 3(6.8\%) cancer patients with COVID-19 who discharged from hospital had positive RT-PCR test results again.

\section{Discussion}

We report here a cohort of 56 cancer patients with laboratory confirmed SARS-CoV-2 infection. In our study, the infection rate of COVID-19 among cancer patients in the single center is estimated to be $3.6 \%$ (79 of 2143 patients), which is significantly higher compared with the general population in previous research(2.3\% [1023 deaths among 44672$]$ )[15]. This result is also in accordance with other studies that reported high rates of infection due to impaired immune function caused by by the disease itself or the treatment[16]. Approximately $21 \%$ (12 of 56 patients) of all hospital patients with cancer dying during their hospital stay. The mortality rate in cancer patients with COVID-19 in our cohort is high. In a cohort of 37 cancer patients with SARS-CoV-2 infection from a single hospital in China, 5 patients patients had died, with a mortality rate of $13.5 \%[8] .3(25 \%)$ of 12 cancer patients with SARS-Cov-2 infection were also reported to have died at a Tertiary Care Hospital in Wuhan, China[17].

Compared with the overall population, the average age of all cancer patients with COVID-19 infections is higher(64 vs 49)[18]. We observe that cancer non-survivors are no older than cancer survivors. In our cohort, gastrointestinal cancers (23\%) are the most commonly encountered tumors. This did not concur with previous studies, in which lung cancer patients were the most common to be infected[19, 20]. However, oneclinical studyhave reported the samefound[8]. Therefor, more multicenter retrospective studies with a larger sample size is required. The clinical symptoms of onset included fever, cough, dyspnea and fatigue. Sputum and broad use of antibiotics were more frequently noted in non-cancer survivors. 
Of all included cancer non-survivors, 6 (50\%) had ARDS and 10 (83\%) required mechanical ventilation. It also supports the notion that patients with cancer were observed to have a higher risk of severe events caused by the SARS-CoV-2[21]. Notably, leukemia and lymphoma patients have a higher probability of severe complications compared with patients with other cancer types. Laboratory tests showed severe lymphopenia, increased levels of lactate dehydrogenase and NT-proBNP in cancer non-survivors compared to cancer survivors. Apart from this, in comparison with the surviving group, non surviving group deteriorated more rapidly (4.5 vs 14.5 days).

With more cancer non-survivors have a history of receiving anticancer treatment within one mouth, suggesting that anti-cancer therapy may have an adverse effects on the severity of COVID-19 among cancer patients. It is noteworthy, however, that significantly more non-survival patients with hematologic malignancies, such as leukemia or lymphoma, in which severe complications such as anemia, thrombocytopenia and profound derangements in coagulation function are inherently more expected. Whether to continue cancer therapy or to delay it is still in controversial, as the risk of cancer progression after stopping cancer therapy remains unknown[3, 8]. In general, treatment delay is not recommended in patients who are at high risk of disease progression or patients who are receiving curative cancer therapy despite the potential risk of COVID-19 infection during anticancer therapy[17]. Thus, more future studies are warranted before any recommendation can be generalized. Intravenous glucocorticoids and immunoglobulin were commonly used in cancer patients with severe SARS-CoV-2, however, with no statistical difference between the two groups,their efficacy remains controversial and their use to treat SARS-CoV-2 infection is also controversial.

It is well known that COVID-19 is associated with cytokine storm and elevated levels of inflammatory markers (interleukin-6, IL-6)[22]. Cytokine release syndrome (CRS) is considered to be the main cause of ARDS in patients infected with SARS-CoV[23]. Similarly, cytokines responses are recognized as important roles in cancer development, progression and metastasis, and are therefore potential prognostic factors[24, 25]. In our study, the degree of cytokine elevation correlates well with adverse clinical outcomes in cancer patients with COVID-19. Moreover, cancer non-survivors had higher concentrations of IL-2R, IL6, and IL10 than those survivors suggesting that the cytokine storm was associated with disease severity. Elevated serum IL-2R, IL6, and IL10 are associated with an unfavorable prognosis and a higher risk of mortality[26, 27]. Therefore, nowadays, the application of drugs that block IL-6 including tocilizumab and sarilumab to treat critically ill patients with CODIV-19 is an active area for research[28, 29].

To our knowledge, this is the first study to pay attention to the follow-up of recovered cancer patients with COVID-19. 3(6.8\%) cancer patients with COVID-19 who met criteria for hospital discharge as a previously described method (asymptomatic, normal radiological images and 2 consecutive negative RTPCR test results) had positive RT-PCR test results(throat swabs) 7 days later. This finding suggests that individual recovered cancer patients still may be virus carriers[30,31]. The infection has not yet been found in contacts, this might be explained by the fact that all reported patients were subject to special care during home quarantine. Currently, there is lack of reliable relevant data about the general population 
in this respect. Thus, the difference between cancer survivors and general infected individual is worthy of more attention.

This study has several limitations. First, while the sample size is larger than the previous studies, only 56 cancer patients were included. With the limited number of cases, it is remain difficult to assess the exactrisk factors and to draw a solid conclusion about disease severity and mortality. At the same time, findings of the p-values of the statistical analysis require caution in their interpretation, and nonsignificant $p$ values do not necessarily exclude difference between cancer survivors and cancer nonsurvivors. We hope the findings showed here will encourage a larger cohort study or some randomly controlled trials if possible. Second, some specific information were incomplete, such as immunoglobulins and Tcell subsets, which resulted in an incomprehensive analysis in disrupted immune function and immunosuppression. The data on other clinical information, however, as discussed in text, are indisputable. Third, this is a retrospective study. This study only describe the clinical course and outcomes of cancer patients with SARS-CoV-2 pneumonia. However, important data on anti-IL-6 therapy are lacking. More effort should be made to solve these questions correctly in future studies.

In conclusion, the infection rate and mortality of COVID-19 among cancer patients are considerable. Cancer non-survivors are characterized by more severe lymphopenia and a higher levels of IL2R, IL6 and IL10. Anti-cancer therapy may have an adverse effects on the severity of COVID-19 among cancer patients. Recovered cancer survivors still may be virus carriers.

\section{Declarations}

Acknowledgements: We thank all patients involved in the study.

Competing interests: The authors declare no competing interests.

\section{References}

1. Zhu N, Zhang D, Wang W, Li X, Yang B, Song J, Zhao X, Huang B, Shi W, Lu R et al (2020) A Novel Coronavirus from Patients with Pneumonia in China, 2019. N Engl J Med. 382:727-733. https://doi.org/10.1056/NEJMoa2001017

2. Fauci AS, Lane HC, Redfield RR (2020) Covid-19 - Navigating the Uncharted. The New England journal of medicine. 382:1268-1269. https://doi.org/10.1056/NEJMe2002387

3. Waisberg F, Enrico D, Angel M, Chacon M (2020) Cancer Treatment Adaptations in the COVID-19 Era. JCO Oncol Pract. OP2000218. https://doi.org/10.1200/OP.20.00218

4. Ruan Q, Yang K, Wang W, Jiang L, Song J (2020) Clinical predictors of mortality due to COVID-19 based on an analysis of data of 150 patients from Wuhan, China. Intensive Care Med. https://doi.org/10.1007/s00134-020-05991-x

5. Liang W, Guan W, Chen R, Wang W, Li J, Xu K, Li C, Ai Q, Lu W, Liang H et al (2020) Cancer patients in SARS-CoV-2 infection: a nationwide analysis in China. The Lancet Oncology. 21:335-337. 
https://doi.org/10.1016/s1470-2045(20)30096-6

6. Yang F, Shi S, Zhu J, Shi J, Dai K, Chen X (2020) Clinical characteristics and outcomes of cancer patients with COVID-19. J Med Virol. https://doi.org/10.1002/jmv.25972

7. Brunello A, Zagonel V (2020) Caring for Patients with Advanced Stage Cancer at the Time of COVID19. Oncologist. https://doi.org/10.1634/theoncologist.2020-0230

8. Ma J, Yin J, Qian Y, Wu Y (2020) Clinical characteristics and prognosis in cancer patients with COVID-19: A single center's retrospective study. J Infect. https://doi.org/10.1016/j.jinf.2020.04.006

9. Al-Quteimat OM, Amer AM (2020) The Impact of the COVID-19 Pandemic on Cancer Patients. Am J Clin Oncol. https://doi.org/10.1097/COC.0000000000000712

10. Miyashita H, Mikami T, Chopra N, Yamada T, Chernyavsky S, Rizk D, Cruz C (2020) Do Patients with Cancer Have a Poorer Prognosis of COVID-19? An Experience in New York City. Ann Oncol. https://doi.org/10.1016/j.annonc.2020.04.006

11. Liang X, Yang C (2020) Full Spectrum of Cancer Patients in SARS-CoV-2 Infection Still Being Described. Clin Oncol (R Coll Radiol). https://doi.org/10.1016/j.clon.2020.03.016

12. Anil I, Arnold R, Benkwitz-Beford S, Branford S, Campton N, Cazier J-B, Cheng V, Curley H, D'Costa J, Edmondson A et al (2020) The UK Coronavirus Cancer Monitoring Project: protecting patients with cancer in the era of COVID-19. The Lancet Oncology. 21:622-624. https://doi.org/10.1016/s14702045(20)30230-8

13. Rassy E, Khoury-Abboud R-M, Ibrahim N, Kattan C, Assi T, Kattan J (2020) What the oncologist needs to know about COVID-19 infection in cancer patients. Future Oncol. https://doi.org/10.2217/fon2020-0312

14. Yang X, Yu Y, Xu J, Shu H, Xia Ja, Liu H, Wu Y, Zhang L, Yu Z, Fang M et al (2020) Clinical course and outcomes of critically ill patients with SARS-CoV-2 pneumonia in Wuhan, China: a single-centered, retrospective, observational study. The Lancet Respiratory Medicine. https://doi.org/10.1016/s22132600(20)30079-5

15. Leung C (2020) Clinical features of deaths in the novel coronavirus epidemic in China. Rev Med Virol. e2103. https://doi.org/10.1002/rmv.2103

16. Sahu KK, Jindal V, Siddiqui AD (2020) Managing COVID-19 in Patients With Cancer: A Double Blow for Oncologists. JCO Oncol Pract. OP2000167. https://doi.org/10.1200/OP.20.00167

17. Yu J, Ouyang W, Chua MLK, Xie C (2020) SARS-CoV-2 Transmission in Patients With Cancer at a Tertiary Care Hospital in Wuhan, China. JAMA Oncol. https://doi.org/10.1001/jamaoncol.2020.0980

18. Huang C, Wang Y, Li X, Ren L, Zhao J, Hu Y, Zhang L, Fan G, Xu J, Gu X et al (2020) Clinical features of patients infected with 2019 novel coronavirus in Wuhan, China. The Lancet. 395:497-506. https://doi.org/10.1016/s0140-6736(20)30183-5

19. Spiess PE, Greene J, Keenan RJ, Paculdo D, Letson GD, Peabody JW (2020) Meeting the challenge of the 2019 novel coronavirus disease in patients with cancer. Cancer.

https://doi.org/10.1002/cncr.32919 
20. Spicer J, Chamberlain C, Papa S (2020) Provision of cancer care during the COVID-19 pandemic. Nat Rev Clin Oncol. https://doi.org/10.1038/s41571-020-0370-6

21. Zhang L, Zhu F, Xie L, Wang C, Wang J, Chen R, Jia P, Guan HQ, Peng L, Chen Y et al (2020) Clinical characteristics of COVID-19-infected cancer patients: a retrospective case study in three hospitals within Wuhan, China. Ann Oncol. https://doi.org/10.1016/j.annonc.2020.03.296

22. Moore JB, June CH (2020) Cytokine release syndrome in severe COVID-19. Science. 368:473-474. https://doi.org/10.1126/science.abb8925

23. (2020) Cytokine Storm Drugs Move from CAR T to COVID-19. Cancer Discov. https://doi.org/10.1158/2159-8290.CD-ND2020-008

24. Lippitz BE (2013) Cytokine patterns in patients with cancer: a systematic review. The Lancet Oncology. 14:e218-e228. https://doi.org/10.1016/s1470-2045(12)70582-x

25. Waldmann TA (2018) Cytokines in Cancer Immunotherapy. Cold Spring Harb Perspect Biol. 10:https://doi.org/10.1101/cshperspect.a028472

26. Sim GC, Radvanyi L (2014) The IL-2 cytokine family in cancer immunotherapy. Cytokine Growth Factor Rev. 25:377-390. https://doi.org/10.1016/j.cytogfr.2014.07.018

27. Taniguchi K, Karin M (2014) IL-6 and related cytokines as the critical lynchpins between inflammation and cancer. Semin Immunol. 26:54-74. https://doi.org/10.1016/j.smim.2014.01.001

28. Xu X, Han M, Li T, Sun W, Wang D, Fu B, Zhou Y, Zheng X, Yang Y, Li X et al (2020) Effective treatment of severe COVID-19 patients with tocilizumab. Proc Natl Acad Sci USA. https://doi.org/10.1073/pnas.2005615117

29. Ascierto PA, Fox B, Urba W, Anderson AC, Atkins MB, Borden EC, Brahmer J, Butterfield LH, Cesano A, Chen $D$ et al (2020) Insights from immuno-oncology: the Society for Immunotherapy of Cancer Statement on access to IL-6-targeting therapies for COVID-19. J Immunother Cancer. 8:https://doi.org/10.1136/jitc-2020-000878

30. Zhang B, Liu S, Dong Y, Zhang L, Zhong Q, Zou Y, Zhang S (2020) Positive rectal swabs in young patients recovered from coronavirus disease 2019 (COVID-19). J Infect. https://doi.org/10.1016/j.jinf.2020.04.023

31. Lan L, Xu D, Ye G, Xia C, Wang S, Li Y, Xu H (2020) Positive RT-PCR Test Results in Patients Recovered From COVID-19. JAMA. https://doi.org/10.1001/jama.2020.2783

\section{Tables}

Table 1 Demographics and baseline characteristics of cancer patients infected with COVID-19 


\begin{tabular}{|c|c|c|c|c|}
\hline & $\begin{array}{l}\text { Cancer } \\
\text { survivors } \\
(\mathrm{N}=44) \\
\end{array}$ & $\begin{array}{l}\text { Cancer } \\
(\mathrm{N}=12)\end{array}$ & $\begin{array}{ll}\text { All patients } & \text { with } \\
\text { cancer }(\mathrm{N}=56) & \end{array}$ & $\begin{array}{l}\mathrm{P} \\
\text { value }\end{array}$ \\
\hline \multirow{2}{*}{$\begin{array}{l}\text { aters } \\
\text { ars }\end{array}$} & & & & \\
\hline & $64(56-71)$ & $64(51-71)$ & $64(54-71)$ & $\begin{array}{l}0.78 \\
0.78\end{array}$ \\
\hline \multirow[b]{2}{*}{ ail } & $23(48 \%)$ & $9(75 \%)$ & $32(57 \%)$ & - \\
\hline & $21(52 \%)$ & $3(25 \%)$ & $24(43 \%)$ & - \\
\hline niological history & $12(27 \%)$ & $4(33 \%)$ & $16(29 \%)$ & 0.96 \\
\hline \multirow{2}{*}{$\begin{array}{l}\text { ng history } \\
\text { morbidity }\end{array}$} & $4(9 \%)$ & $1(8 \%)$ & $5(9 \%)$ & 1.00 \\
\hline & $23(52 \%)$ & $4(33 \%)$ & $27(48 \%)$ & 0.24 \\
\hline etion & $21(48 \%)$ & $2(17 \%)$ & $23(41 \%)$ & 0.11 \\
\hline (n) & $7(16 \%)$ & & $7(12.5 \%)$ & 0.33 \\
\hline c cardiac disease & $5(11 \%)$ & 0 & $5(9 \%)$ & 0.51 \\
\hline c pulmonary disease & $1(2 \%)$ & & $1(2 \%)$ & 1.00 \\
\hline \multirow{2}{*}{$\begin{array}{l}\text { is } \\
\text { ll nervous system diseases }\end{array}$} & $1(2 \%)$ & $1(8 \%)$ & $2(4 \%)$ & 0.90 \\
\hline & 0 & $2(17 \%)$ & $2(4 \%)$ & 0.06 \\
\hline \multicolumn{5}{|l|}{$\begin{array}{l}\text { and symptoms on } \\
\text { sion }\end{array}$} \\
\hline & $36(82 \%)$ & $11(92 \%)$ & $47(84 \%)$ & 0.41 \\
\hline & $30(62 \%)$ & $9(75 \%)$ & $39(70 \%)$ & 0.65 \\
\hline a & $8(18 \%)$ & $6(50 \%)$ & $14(25 \%)$ & 0.02 \\
\hline \multirow{2}{*}{$\begin{array}{l}\text { sea } \\
\text { эа }\end{array}$} & $26(60 \%)$ & $8(67 \%)$ & $34(61 \%)$ & 0.63 \\
\hline & $9(21 \%)$ & $2(17 \%)$ & $11(20 \%)$ & 1.00 \\
\hline a & $2(5 \%)$ & $2(17 \%)$ & $4(7 \%)$ & 0.42 \\
\hline \multirow{2}{*}{ ng } & $1(2 \%)$ & $2(17 \%)$ & $3(5 \%)$ & 0.22 \\
\hline & $16(36 \%)$ & $2(17 \%)$ & $18(32 \%)$ & 0.34 \\
\hline & $6(14 \%)$ & $1(8 \%)$ & $7(13 \%)$ & 1.00 \\
\hline $\begin{array}{l}\text { lar pain } \\
\text { she }\end{array}$ & $2(5 \%$ & & $2(3.6 \%)$ & 1.00 \\
\hline $\begin{array}{c}\text { from } \\
\text { alization }\end{array}$ & $14.5(6.3-19)$ & $4.5(2.3-9.5)$ & $10(4-17)$ & 0.02 \\
\hline \multirow{3}{*}{$\begin{array}{l}\text { ate, beats } / \mathrm{min} \\
\text { atory rate } 24 \text {, beats } / \mathrm{min} \\
\text { ic pressure, } \mathrm{mm} \mathrm{Hg}\end{array}$} & $88(70-106)$ & 101(86-116) & $91(73-109)$ & 0.03 \\
\hline & $5(11 \%)$ & $2(16 \%)$ & $7(13 \%)$ & 0.35 \\
\hline & $\begin{array}{l}136(116- \\
156)\end{array}$ & $124(102-146)$ & 133(112-154) & 0.08 \\
\hline oxygen saturation $\square 93 \%$ & $9(20 \%)$ & $6(50 \%)$ & $15(27 \%)$ & 0.04 \\
\hline
\end{tabular}

Data are median (IQR), mean $( \pm \mathrm{SD})$ or $\mathrm{n}(\%)$. p values comparing cancer survivors and non-cancer survivors are from $\chi \square$ test, Fisher's exact test, independent sample t test, or Mann-Whitney U test. COVID-19=2019 novel coronavirus disease.

Table 2 Laboratory findings of cancer patients infected with COVID-19 on admission to hospital. 


\begin{tabular}{|c|c|c|c|c|c|}
\hline & $\begin{array}{l}\text { Cancer } \\
\text { survivors } \\
(\mathrm{N}=44)\end{array}$ & $\begin{array}{ll}\text { Cancer } & \text { non-survivors } \\
(\mathrm{N}=12) & \end{array}$ & $\begin{array}{l}\text { All patients } \\
\text { cancer }(\mathrm{N}=56)\end{array}$ & with & $\mathrm{P}$ value \\
\hline blood cell count, $\times 10 \square / L$ & $5.5(4.4-7.1)$ & $5.2(3.1-7.1)$ & $5.5(4.3-7.1)$ & & 0.60 \\
\hline locyte count, $\times 10 \square / \mathrm{L}$ & $1.1(0.7-1.5)$ & $0.5(0.3-0.7)$ & $1.0(0.6-1.4)$ & & 0.01 \\
\hline :yte, × 10ם/L & $0.5(0.3-0.7)$ & $0.5(0.1-0.9)$ & $0.5(0.3-0.8)$ & & 0.73 \\
\hline globin, g/L & 115(91-139) & $87(48-126)$ & $109(79-139)$ & & 0.03 \\
\hline ocrit, \% & $34(30-39)$ & $22(18-34)$ & $33(26-39)$ & & 0.01 \\
\hline st count, $\times 10 \square / L$ & $\begin{array}{l}230(123- \\
337)\end{array}$ & $114(11-217)$ & $205(90-320)$ & & 0.01 \\
\hline ombin time, $\mathrm{s}$ & $14(14-14)$ & $15(14-17)$ & $14(14-15)$ & & 0.003 \\
\hline ted partial & \multicolumn{4}{|c|}{ Joplastin time, s } & 0.10 \\
\hline gen, $g / L$ & $5.0(3.3-6.7)$ & $4.6(2.8-6.4)$ & $4.9(2.9-6.3)$ & & 0.52 \\
\hline $\mathrm{r}, \mathrm{mg} / \mathrm{L}$ & $1.1(0.4-2.5)$ & $1.3(0.6-4.2)$ & $1.5(0.5-2.5)$ & & 0.34 \\
\hline e aminotransferase, U/L & $20(16-37)$ & $20(9-36)$ & $20(15-37)$ & & 0.42 \\
\hline ate aminotransferase, $\mathrm{U} / \mathrm{L}$ & $22(18-31)$ & $37(12-43)$ & $23(18-38)$ & & 0.45 \\
\hline in, $g / L$ & $35(30-40)$ & $34(26-42)$ & $35(29-41)$ & & 0.34 \\
\hline e dehydrogenase, U/L & $\begin{array}{l}239(200- \\
318)\end{array}$ & $453(179-551)$ & $252(185-390)$ & & 0.048 \\
\hline ium, mmol/L & $4.1(3.8-4.4)$ & $3.8(3.5-4.5)$ & $4.1(3.7-4.4)$ & & 0.39 \\
\hline nine, $\mu \mathrm{mol} / \mathrm{L}$ & $66(55-83)$ & $55(43-97)$ & $64(52-83)$ & & 0.23 \\
\hline itrogen $\mathrm{mmol} / \mathrm{L}$ & $4.3(3.5-6.1)$ & $5.5(3.4-7.6)$ & $4.5(3.5-6.5)$ & & 0.5 \\
\hline sensitive troponin $\mathrm{I}, \mathrm{pg} / \mathrm{mL}$ & $2.7(1.9-8.9)$ & $5.5(1.9-105)$ & $3.0(1.9-13.6)$ & & 0.23 \\
\hline )BNP, pg/mL & $137(48-314)$ & $565(370-1418)$ & $237(62-451)$ & & $<0.0001$ \\
\hline ensitive-c-reactive & $45(6-88)$ & $80(41-105)$ & $54(8-100)$ & & 0.67 \\
\hline \multirow{2}{*}{\multicolumn{6}{|c|}{$\begin{array}{l}\text { l, } \mathrm{mg} / \mathrm{L} \\
\text { ne profiles }\end{array}$}} \\
\hline & & & & & \\
\hline $\mathrm{g} / \mathrm{mL}$ & $5.0(5.0-5.3)$ & $5.0(5.0-5.0)$ & $5.0(5.0-5.0)$ & & 0.11 \\
\hline $\mathrm{U} / \mathrm{mL}$ & $\begin{array}{l}597(397- \\
916)\end{array}$ & $1384(678-1823)$ & 628(402-1199) & & 0.02 \\
\hline $\mathrm{g} / \mathrm{mL}$ & $9(2.8-34.9)$ & $42(22-65)$ & $15.2(3.3-42.9)$ & & 0.01 \\
\hline $\mathrm{y} / \mathrm{mL}$ & $13(7-21)$ & $21(8-63)$ & $12.8(7.4-12.6)$ & & 0.16 \\
\hline $\mathrm{pg} / \mathrm{mL}$ & $5(5-6.3)$ & $9.3(5-15.6)$ & $5(5-8)$ & & 0.03 \\
\hline$\alpha, \mathrm{pg} / \mathrm{mL}$ & $8.7(6.6-12.6)$ & $10.2(8.9-13.8)$ & $9.1(6.9-12.9)$ & & 0.13 \\
\hline $\begin{array}{l}\text { al involvement of chest } \\
\text { raphs }\end{array}$ & $31(70 \%)$ & $7(58 \%)$ & $38(68 \%)$ & & 1.00 \\
\hline
\end{tabular}

Data are median $(\mathrm{IQR})$, mean $( \pm \mathrm{SD})$ or $\mathrm{n}(\%)$. $\mathrm{p}$ values comparing cancer survivors and non-cancer survivors are from $\chi \square$ test, Fisher's exact test, independent sample t test, or Mann-Whitney U test. COVID-19=2019 novel coronavirus disease.

Table 3 Major cancer type, respiratory complication and treatment of cancer patients infected with COVID-19 


\begin{tabular}{|c|c|c|c|c|c|}
\hline & $\begin{array}{l}\text { Cancer } \\
\text { survivors } \\
(\mathrm{N}=44)\end{array}$ & $\begin{array}{ll}\text { Cancer } & \text { non-survivors } \\
(\mathrm{N}=12) & \end{array}$ & $\begin{array}{l}\text { All patients } \\
\text { cancer }(\mathrm{N}=56)\end{array}$ & with & $\mathrm{P}$ value \\
\hline \multicolumn{6}{|l|}{$\overline{\text { r cancer type }}$} \\
\hline ointestinal cancers & $10(23 \%)$ & $3(25 \%)$ & $13(23 \%)$ & & 1.00 \\
\hline emia and lymphoma & $5(11 \%)$ & $5(42 \%)$ & $10(18 \%)$ & & 0.02 \\
\hline cancer & $7(16 \%)$ & $2(17 \%)$ & $9(16 \%)$ & & 1.00 \\
\hline əy and bladder cancers & $4(9 \%)$ & $2(17 \%)$ & $6(11 \%)$ & & 0.82 \\
\hline st cancer & $4(9 \%)$ & 0 & $4(7 \%)$ & & 0.65 \\
\hline cological cancer & $4(9 \%)$ & 0 & $4(7 \%)$ & & 0.65 \\
\hline $\begin{array}{l}\text { r cancers } \\
\text { iratory complication }\end{array}$ & $10(20 \%)$ & 0 & $10(18 \%)$ & & 0.16 \\
\hline $\begin{array}{l}\text { respiratory distress } \\
\text { ome(ARDS) }\end{array}$ & $2(5 \%)$ & $6(50 \%)$ & $8(14 \%)$ & & $<0.0001$ \\
\hline tment & & & & & \\
\hline $\begin{array}{l}\text { umor therapy } \\
\text { in one month) }\end{array}$ & $3(6.8 \%)$ & $4(33.3 \%)$ & $7(12.5 \%)$ & & 0.049 \\
\hline Ianical ventilation & $4(9 \%)$ & $10(83 \%)$ & $14(25 \%)$ & & $<0.0001$ \\
\hline 1 replacement therapy & $7(16 \%)$ & $2(17 \%)$ & $9(16 \%)$ & & 1.00 \\
\hline iral agents & $34(77 \%)$ & $12(100 \%)$ & $46(82 \%)$ & & 0.07 \\
\hline acterial agents & $24(55 \%)$ & $12(100 \%)$ & $36(64 \%)$ & & 0.04 \\
\hline corticoids & $13(30 \%)$ & $6(50 \%)$ & $19(34 \%)$ & & 0.19 \\
\hline גnoglobulin & $7(16 \%)$ & $5(42 \%)$ & $12(21 \%)$ & & 0.054 \\
\hline ive RT-PCR after discharge & $3(6.8 \%)$ & - & - & & - \\
\hline
\end{tabular}

Data are $n(\%)$. p values comparing cancer survivors and non-cancer survivors are from $\chi \square$ test, or Fisher's exact test. COVID-19=2019 novel coronavirus disease.

\section{Figures}


2143 patients with confirmed COVID-19 as of Mar 29, 2020

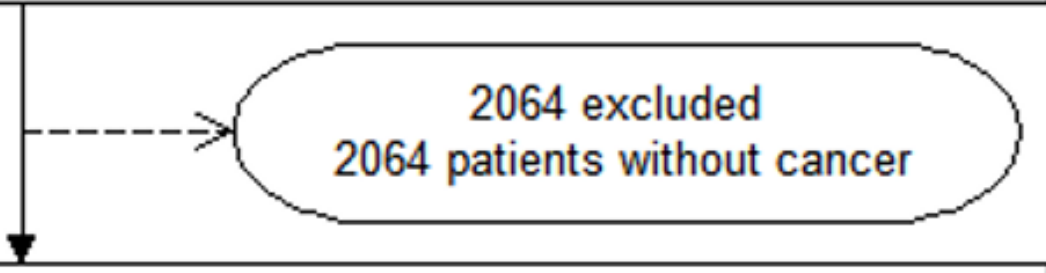

79 patients with cancer confirmed COVID-19

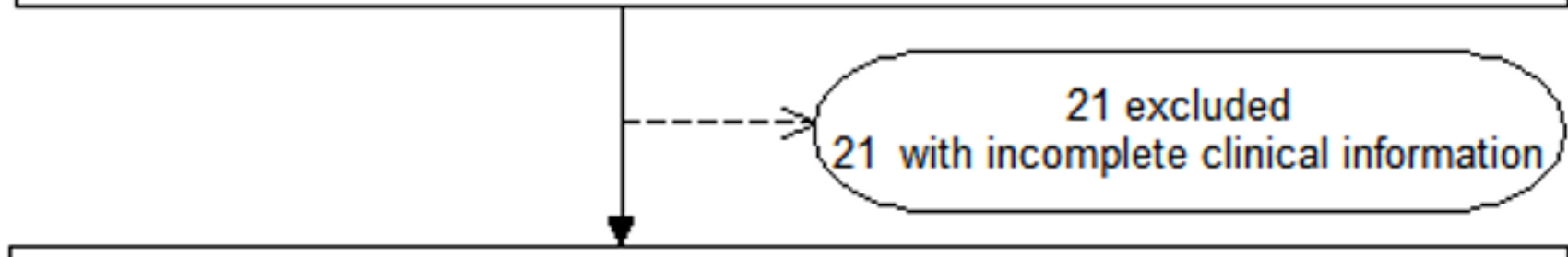

58 patients with cancer added in study

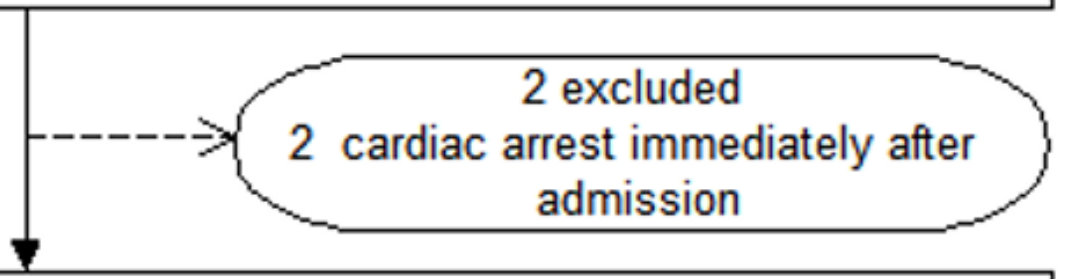

56 patients with cancer included in study

Figure 1

Study flow diagram. COVID-19=2019 novel coronavirus disease

\section{Supplementary Files}

This is a list of supplementary files associated with this preprint. Click to download.

- supplementarymaterial.xls 